\title{
Investigation of Distribution of Beta -Thalassemia Hereditary Mutations in Gaziantep and the Surrounding Areas
}

\author{
Serdar Öztuzcu ${ }^{1}$ Ali Bay², Gülper Nacarkahyaa ${ }^{1}$, Mustafa Ulaşlı1 ${ }^{1}$ Elif Aktekinn², Sinan Akbayram², Murat \\ Korkmaz', Füsun Tuşgül' ${ }^{1}$, Ahmet Arslan' \\ 'Gaziantep Üniversitesi, Tıp Fakültesi, Tıbbi Biyoloji Anabilim Dalı, Gaziantep, Türkiye \\ ${ }^{2}$ Gaziantep Üniversitesi, Tıp Fakültesi, Pediatrik Hematoloji Bilim Dalı, Gaziantep, Türkiye
}

\begin{abstract}
Introduction: Beta-thalassemia is the most common autosomal recessive disease. More than 200 different mutations determined in beta-globin gene. Beta thalassemia disease has a severe clinical picture. Treatment of the diseases should be maintained properly otherwise quality of life and life period can be affected. In this study, we tried to reveal inherited beta-thalassemia mutations in surrounding areas of Gaziantep.
\end{abstract}

Material and Methods: In this study, we included 208 patients who applied with beta -thalassemia suspicion to the pediatric hematology clinic (age range 4-14). In that study, 138 patients with homozygous mutations and 70 patients' heterozygous mutations were identified. HBB gene was sequenced by Sanger DNA Sequencing method.

Results: Most common homozygote mutations are IVS I-110 G>A, IVS I-1 G>A, IVS II-1 G>A, the heterozygote mutations are IVS I-110 G>A, IVS II-1 G>A, codon 8 (AA) del. The incidence of IVS $1.110(\mathrm{G}>\mathrm{A})$ mutation is $24 \%, 28$ in homozygote patients, $29.7 \%$ in heterozygote patients. The $8 \%$ homozygote patients and $19.7 \%$ heterozygote patients were effected with IVS $1.110(\mathrm{G}>\mathrm{A})$ mutation.

Conclusion: The consanguinity marriages are very abundant particularly in our region due to fact that we are able to see many autosomal recessive diseased in our region. Reducing incidence of autosomal recessive disease by given genetic counseling could help the solution but it is still a major problem. J Clin Exp Invest 2016; 7(4): 265-268

Key Words: Beta Thalassemia, Beta-globin, HBB

\section{GíRiş}

Beta talasemi, birçok Akdeniz ülkesinde ve Türkiye de sıklıkla gözlenen tek gen hastalıklarından olup, otozomal resesif geçiş gösteren, mikrositoz ve hemolitik anemi ile karakterize bir hastalıktır [1-3]. Dünyada her yıl 56.000 talasemili hasta doğmaktadır [4]. Talasemi taşıyıcılığı oranı Dünya Sağlık Örgütü (DSÖ) verilerine göre \% 5.1 olup, ülkelere ve ülkeler içindeki farklı yerleşim birimlerine göre değişmektedir. Coğrafi bölgeye özgü bazı mutasyonlar da vardır [5]. Gebe kadınların $\% 7$ 'si, Dünya nüfusunun $\% \quad 5,2$ 'si $\mathrm{Hb}$ bozukluklarından etkilenmektedir. Beta talasemi taşıyıcılığı oranı Türkiye'nin bazı yörelerinde \% 10‘a kadar çıkmakla birlikte, Türkiye genelinde \% 2,1 'dir [6,7]. Gaziantep ilinde görülme sıklığı ise \% 1,8'dir [8]. Güneydoğu Anadolu bölgesinde doğum hızının yüksekliği ve bunun yanı sıra akraba evliliğinin sıklığı Türkiye'de beklenenin üzerinde talasemili çocuk doğma intimalini artırmaktadır $[9,10]$. ß-talasemilerde klinik heterojeniteden mutasyonların çeşitliliği sorumludur. Birçok mutasyonda ß-geni hiç eksprese olmazken $\left(\AA^{\circ}\right)$, diğer mutasyonlarda $\beta$ geninde ekspresyonda azalma söz konusudur (ß+) [11]. Günümüzde 200 den fazla $ß$ globin geninde mutasyonun bulunduğu belirtilmektedir. Bu mutasyonlar çerçeve kayması mutasyonları, promotor bölge mutasyonları, RNA işleme (splicing) mutasyonları, nonsens mutasyonlar diye bildiğimiz dur kodonuna neden olan mutasyonlar ya da, mRNA'nın 5'ucuna CAP 3' ucuna poli $A$ kuyruğunun eklenmesi ile ilişkili mutasyonlar olarak sınıflandırılabilir. $B$ talasemi de genin büyük bir kısmının kaybına neden olan mutasyonlar nadirdir. Eğer bir tane hatalı ß 
globin geni varsa $\beta$ talasemi minör veya $\beta$ talasemi taşıyıcısı, iki gende hatalı ise $B$ talasemi majör hastalığı meydana gelir $[12,13]$. Türk halkında 40'dan fazla mutasyon tanımlanmıştır. Bunlar arasında en yaygın 7 mutasyon (IVS 1.110, kodon 8, IVS 2.1, IVS 1.1, IVS 2.745) tüm mutasyonların yaklaşık \% 72'sini oluşturmaktadır [14,15]. Beta-globin gen mutasyonlarının ortaya çıkarılması, heterozigot bireyleri içeren taşıyıcıların belirlenmesi ya da beta-talaseminin erken prenatal tanısı ve tedavi projeleri için gereklidir. Bu amaçla günümüzde allele özgü primer analizleri (ARMS) tekniği, oligonukleotid hibridizasyonu, restriksiyon endonükleaz analizi ve beta-globin geninin DNA dizi analizi gibi doğrudan polimeraz zincir reaksiyonuna dayalı yöntemler kullanılmaktadır $[16,17]$. Bu çalışmada Gaziantep Üniversitesi Tıp Fakültesi Şahinbey Hastanesi' sinde teşhis ve tedavisi yapılmakta olan beta talasemi hastalarının beta-globin geninde taşınan mutasyonlarının belirlenmesi amaçlanmıştır.

\section{HASTALAR VE METOT}

$\mathrm{Bu}$ çalışmaya Gaziantep Üniversitesi Tıp Fakültesi Şahinbey Hastanesi'ne Kasım 2010Ocak 2016 tarihleri arası beta-talasemi şüphesiyle Pediatrik Hematoloji Kliniğine başvuran yaş aralığı 0-14 olan 208 hasta dahil edilmiştir. Hastalardan $2 \mathrm{~mL}$ venöz kan örneği EDTA içeren tüplere alınmıştır. $\mathrm{Bu}$ amaçla alınan kan örneklerinden HBB gen mutasyonlarını tespit et $\neg$ mek için alınan kan örneklerinden DNA izolasyonu yapılmıştır. İn vitro multiplex amplifikasyon (multiplex PCR)'un ardından \%2 lik agaroz jelde bantların gözlenmesi ile multiplex PCR kontrol edilmiştir. Sanger dizi analizi yöntemiyle HBB geni dizilenmiş ve mutasyon analizi yapılmıştır (Hitachi AB, Applied Biosystem Genetic Analyzer 3130, USA). Cihazda Sequencing Analyses programı (SeqScape Software v2.6) ile DNA dizi analizi işlemi gerçekleştirilmiştir.

\section{BULGULAR}

Çalışma sonucu 70 hastada homozigot mutasyon 138 hastada heterozigot mutasyon tespit edilmiştir. Mutasyon tespit edilen 70 hastanın HBB geni homozigotmutasyonuları sıklığı 17 adet IVS I-110 G>A (\% 24,28), 10 adet IVS I-1 G>A (\% 14,28), 9 adet IVS II-1 G>A (\% $12,85)$, IVS I-6 T>C (\% 8,57), 4 adet IVS I-130 G>C (\% 5,71), 4 adet codon 8 (-AA) del (\%
5,71), 4 adet codon $39 \mathrm{C}>\mathrm{T}(\%$ 5,71), 4 adet codon $17 \quad \mathrm{~A}>\mathrm{T} \quad(\% \quad 5,71), 3$ adet $30 \mathrm{~T}>\mathrm{A}$ intermedia (\% 4,28), 2 adet codon 5 (-CT) del $(\% 2,85), 1$ adet $30-T$ delesyonu $(\% 1,42), 1$ adet 5' UTR -30 T>A (\% 1,42), 1 adet codon 44 (C) del $(\% 1,42), 1$ adet codon $82(-\mathrm{G})$ del $(\%$ 1,42), 1 adet codon 82/83 (-G) del $(\% 1,42), 1$ adet codon $9 / 10(+T)$ insersiyon (\% 1,42), 1 adet IVS II-848 C>A (\% 1,42) olarak saptandı. (Tablo1).

Table 1. Belirlenen homozigot beta-globin gen mutasyonlarını taşıyan kromozomların frekansı.

Mutasyon Tipi Hasta Sayısı (\%)

\begin{tabular}{ll}
\hline IVS I-110 G>A & $17(24,28)$ \\
\hline IVS I-1 G>A & $10(14,28)$ \\
\hline IVS II-1 G>A & $9(12,85)$ \\
\hline IVS I-6 T>C & $9(8,57)$ \\
\hline IVS I-130 G>C & $4(5,71)$ \\
\hline codon 8 (-AA) del & $4(5,71)$ \\
\hline codon 39 C>T & $4(5,71)$ \\
\hline codon 17 A>T & $4(5,71)$ \\
\hline 30 T>A intermedia) & $3(4,28)$ \\
\hline codon 5 (-CT) del & $2(2,85)$ \\
\hline 30 - T delesyonu & $1(1,42)$ \\
\hline 5' UTR -30 T>A & $1(1,42)$ \\
\hline codon 44 -(C) del), & $1(1,42)$ \\
\hline codon 82 (-G) del & $1(1,42)$ \\
\hline codon $82 / 83$ (-G) del & $1(1,42)$ \\
\hline codon9/10 (+T) insersiyon & $1(1,42)$ \\
\hline IVS II-848 C>A & $1(1,42)$ \\
\hline & \\
\hline
\end{tabular}


Table 2. Belirlenen heterozigot beta-globin gen mutasyonlarını taşıyan kromozomların frekansı.

\begin{tabular}{|c|c|}
\hline Mutasyon Tipi & Hasta Sayısı (\%) \\
\hline IVS I-110 G>A & $41(29,71)$ \\
\hline codon 8 (-AA) del & $15(10,86)$ \\
\hline IVS II-1 G>A & $15(10,86)$ \\
\hline IVS I-1 G>A & $13(9,42)$ \\
\hline IVS I-6 T>C & $10(7,24)$ \\
\hline codon $39 \mathrm{C}>\mathrm{T}$ & $9(6,52)$ \\
\hline codon $44-(C)$ del), & $6(4,34)$ \\
\hline codon $121 \mathrm{G}>\mathrm{C}$ & $5(3,62)$ \\
\hline codon $17 \mathrm{~A}>\mathrm{T}$ & $4(2,89)$ \\
\hline codon9/10(+T) insersiyon & $3(2,17)$ \\
\hline codon 5 (-CT) del & $2(1,44)$ \\
\hline codon $82 / 83(-G)$ del & $2(1,44)$ \\
\hline IVS I-130 G>C & $2(1,44)$ \\
\hline 5' UTR -30 T>A & $2(1,44)$ \\
\hline codon $126 \mathrm{~T}>\mathrm{C}$ & $1(0,72)$ \\
\hline codon 15 G>A & $1(0,72)$ \\
\hline codon $36(-T)$ del & $1(0,72)$ \\
\hline codon $6 \mathrm{~A}>\mathrm{T}$ & $1(0,72)$ \\
\hline codon 74/75 (-C) del & $1(0,72)$ \\
\hline codon $8 / 9(+G)$ insersiyon & $1(0,72)$ \\
\hline IVS II-26 T>G & $1(0,72)$ \\
\hline
\end{tabular}

\section{TARTIŞMA}

Geniş çeşitlilikte mutasyona sahip olan Beta talasemiyi basite indirgeyen faktör, tüm mutasyonların etnik gruplarda farklılık göstermesi ve her toplumda görülmemesidir. Genetik temelli çalışmaların yapılması Beta talasemi araştırmalarında, önemli katkılar sağlamıştır. Çalışma grubu içerisinde bu mutasyonu taşıyan 138 heterozigot ve 70 homozigot birey bulunmaktadır. Çalışmamızda en sık rastlanan mutasyon IVS 1.110 (G>A) olup, tüm mutant allellerin homozigot olarak $\% 24,28$ ini, heterozigot olarak \%29,71 ini oluşturmaktadır. Ayrıca 17 kişide homozigot, 41 kişide heterozigot IVS 1.110 (G>A) mutasyonu bulunmaktadır.

Ince ve arkadaşları Güneydoğu bölgesinde en yaygın $\beta$ talasemi mutasyonunun yine IVS I-110 olduğunu $(\% 27,8)$ ve bunu $\% 11,1$ oranlarında IVS I-6 ve Cd 8, \% 8,3 oranında IVS II- 1 ve \% 5,5 oranında IVS II-745 mutasyonlarının izlediğini bildirmişlerdir [18].

Tadmouri ve arkadaşları yaptıkları çalışmada Türkiye'de en yaygın görülen $\beta$ talasemi mutasyonunun IVS I-110 olduğunu ve bunu IVS I-6, Cd 8, IVS I-1, IVS II-745, IVS II-1, Cd 39, -30 ve Cd 5 mutasyonlarının izlediğini bildirmişlerdir. IVS I-110 mutasyonunun bölgelere göre dağılımının Karadeniz Bölgesi için \%31,0, Ege ve Akdeniz Bölgesi için \% 42,4, Marmara Bölgesi için \% 34,1, İç Anadolu için \% 52,3, Batı Anadolu için \% 3,1ve Güneybatı Anadolu için $\% 26,4$ olarak değiştiğini rapor etmişlerdir [19]. Bir başka çalışmalarında ise yaygın olarak görülen 7 tane mutasyonun Türk populasyonunda görülen mutasyonların \% 7'sini oluşturduğunu ve bunların sırasıyla \% 41 IVS I$110, \% 13$ IVS I-6, \% 8 IVS II- $1, \% 6$ Cd8, \% 5 IVS I-1 ve \% 5 IVS II-745 mutasyonları olduğunu bildirmişlerdir [15].

Akdeniz'in doğusunda görülen bu mutasyonların baskın bir mutasyon olduğu belirtilmektedir. Bu tür çalışmalar ile akraba evliliklerinin yaygın olduğu bölgemizde beta talasemi ile igili olası riskler anlatılarak ebeveynlerin prenatal tanıya yönlendirilmesi sağlanacaktır. 
Declaration of Conflicting Interests: The authors declare that they have no conflict of interest.

Financial Disclosure: No financial support was received

\section{KAYNAKLAR}

1. Tuzmen S, Schechter AN. Genetic diseases of hemoglobin: diagnostic methods for elucidating $\beta$ thalassemia mutations. Blood Reviews 2001; 15 (1):19-29.

2. Kazazian HH Jr, Boehm CD. Molecular basis and prenatal diagnosis of beta-thalassemia. Blood 1988;72 (4):1107-1116.

3. Aydinok Y, Oztop S, Nişli G, Kavakli K. Prevalence of beta-thalassaemia trait in 1124 students from Aegean region of Turkey. J Trop Pediatr 1997; 43 (3):184-5.

4. Canatan D, Kose MR, Ustundag M, Haznedaroglu D, Ozbas S. Hemoglobinopathy control program in Turkey. Community Genet 2006; 9 (2):124-126.

5 Baş M. Beta Talasemi Major Hastalarinda Oral Deferasirox ve Diğer Demir Şelasyon Tedavilerinin Kardiak, Hepatik ve Endokrin Organlardaki Demir Birikimi Üzerine Etkisinin $\mathrm{T}^{*} \mathrm{Mrg}$ ile Değerlendirilmesi. Hacettep Üniversitesi Tıp Fakültesi Dahili Tıp Bilimleri Tez Koleksiyonu, 2014. http://hdl.handle.net/11655/804

6. Başak AN. Hemoglobinopatilerin Prenatal Tanısı ve Türkiye'de $\beta$-Talasemi'nin Moleküler Temeli. Prenatal Tanı ve Tedavi, Editör: Kılıç Aydınlı, Perspektiv, Prestij Matbaacılık, İstanbul, 1992.

7. Başak AN. The molecular pathology of $\beta$ thalassemia in Turkey: the Boğaziçi University experience. Hemoglobin 2007; 31: 233-241.

8. Gurbak M, Sivasli E, Coskun Y, Bozkurt Al, Ergin A. Prevalence and hematological characteristics of beta-thalassemia trait in Gaziantep urban area, Turkey. Pediatr Hematol Oncol 2006; 23 (5):419-25.

9. Gumruk F. Hemoglobinopatilerin tanı ve tedavisinde yenilikler. Turkiye Klinikleri J Pediatr Sci 2007; 3 (10):1-4.

10. Günçag D. Hemolitik Anemiler. Klinik Hematoloji. Dinçol G, Pekçelen Y, Atamer T, Sargın D, Nalçacı M, Aktan M, Besısık SK (editör) İstanbul: Nobel Tıp Kitabevi 2003; s: 87-152.

11. Şule Ul. Beta Talasemi Kliniği ve Tanısı. Türkiye Klinikleri J Hematol Special Topics 2010; 3 (1): 14-17.

12. Kutlu M, Cekmis $H$, Basak $M$, et al. Thalassemia. Bakırköy Tıp Dergisi 2006; 2 (2): 33-40.
13. Gülbay G, Yeşilada E, Aydoğdu İ, Özgen Ü, Otlu G. Malatya'da Beta-Talasemi Mutasyonları. İnönü Üniversitesi Tıp Fakültesi Dergisi 2009; 16 (4). 209212.

14. Tadmouri GO, Garguier N, Demont J, Perrin P, Başak AN. History and origin of $\beta$-thalassemia in Turkey: sequence haplotype diversity of $\beta$-globin genes. Hum Biol 2001; 73 (5):661-674.

15. Tadmouri GO, Başak AN. Beta-thalassemia in Turkey: a review of the clinical, epidemiological, molecular, and evolutionary aspects. Hemoglobin 2001; 25 (2):227-239.

16. Yıldız S, Atalay A, Bağcı H, Atalay EÖ. Betathalassemia mutations in Denizli province of Turkey. Turk J Haematol 2005; 5; 22 (1):19-23.

17. Keser I, Manguoglu E, Güzeloglu Kayışlı Ö, et al. Prenatal Diagnosis of beta-Thalassemia in the Antalya Province. Turk J Med Science 2005 (35):253255.

18. Ince $\mathrm{HH}$, Ayyildiz $\mathrm{O}$, Kalkanli $\mathrm{S}$, Batun $\mathrm{S}$, Muftuoglu E. Molecular basis of beta-thalassemia mutations in Diyarbakir in the southeastern region of Turkey. Hemoglobin 2003; 27 (4):275-278.

19. Tadmouri GO, Tüzmen $S$, Ozçelik $H$, et al. Molecular and population genetic analyses of betathalassemia in Turkey. Am J Hematol 1998; 57: 215220. 